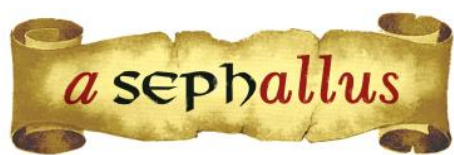

Revista aSEPHallus de Orientação Lacaniana

Núcleo Sephora de Pesquisa sobre o Moderno e o Contemporâneo

ISSN $1809-709 \mathrm{X}$

\title{
Jovens, escritores e a invenção nas linguagens artísticas urbanas - um diário de campo
}

\author{
Bruna Simões de Albuquerque \\ Doutoranda em Conhecimento e Inclusão Social em Educação pela Faculdade de Educação (FaE) da \\ Universidade Federal de Minas Gerais (UFMG). \\ Pesquisadora do NIPSE (Núcleo Interdisciplinar de Pesquisa em Psicanálise e Educação) \\ da FaE-UFMG. \\ Psicóloga (UFMG), Mestre em Psicopatologia e Estudos Psicanalíticos (Université de Strasbourg, \\ França). \\ E-mail: bruquerque@gmail.com
}

\begin{abstract}
Ana Lydia Santiago
Psicanalista. Professora do Programa de Pós-Graduação em Educação: Conhecimento e Inclusão social da Faculdade de Educação, da UFMG, Belo Horizonte, Minas Gerais. Membro da EBP.
\end{abstract}

E-mail: analydia.ebp@gmail.com

\begin{abstract}
Resumo: Esse artigo apresenta o diário de campo das entrevistas de nossa pesquisa com jovens e com escritores, que visa investigar a dimensão da invenção a partir das linguagens artísticas urbanas. Objetivamos apreender o modo como se dá o tratamento particular da linguagem feito por cada sujeito. Apresentamos dois momentos. Primeiro, uma leitura daquilo que observamos e aprendemos com o percurso das entrevistas: quem entrevistamos, o que queríamos saber, efeitos dos encontros e desencontros. Em um segundo momento, aquilo que foi possível isolar: encontramos nas entrevistas uma lógica de saída do túnel da adolescência, que articula esse momento da mais delicada transição, linguagem e invenção. Tal lógica é apresentada por meio de um fragmento de uma entrevista com uma jovem do rap.
\end{abstract}

Palavras-chave: psicanálise; jovens; adolescência; linguagem; cidade.

\begin{abstract}
Jeunes, écrivains et l'invention dans les langages artistiques urbains - un cahier de bord
Cet article présente le cahier de bord des entretiens de notre recherche, avec des jeunes et des écrivains, que vise investiguer la dimension de l'invention à partir des langages artistiques urbains. Notre objectif est celui de saisir la façon dont se déroule le traitement particulier du langage par chacun. Nous présentons deux moments, d'abord une première lecture de ce que nous avons observé et appris pendant le parcours des entretiens: à qui nous avons posé des questions, qu'est-ce qu'on voulait savoir, des effets des rencontres et non rencontres. Dans un deuxième temps, ce qu'il a été possible d'isoler: nous avons trouvé dans les entretiens une logique de sortie du tunnel de l'adolescence qui articule l'adolescence, le langage et l'invention. Cette logique é présentée par un fragment d'entretien avec une jeune fille du rap.
\end{abstract}

Mots-clés: psychanalyse; jeunes; adolescence; langage; ville.

Youth, writers and invention in artistic urban languages - a field journal

This article presents a field journal with the interviews with young people and with writers, which intends to investigate the significance of the invention through the artistic urban languages. We aim to learn how these different groups treat language in their own way. Two different moments are presented. First, a preliminary analysis about what we have observed and learned with the interviews: who we interviewed, what questions were asked, the effects of the meetings and disagreements. Second, what we could point out: in the interviews we could observe a logic of exit of the teenage tunnel that articulates adolescence, language and invention. This logic is presented through a fragment of an interview with a young rapper.

Keywords: psychoanalysis; youth; adolescence; language; city. 


\section{Jovens, escritores e a invenção nas linguagens artísticas urbanas - um diário de campo}

Bruna Simões de Albuquerque \& Ana Lydia Santiago

\section{Introdução}

O adulto que convive ou trabalha com jovens não é indiferente ao uso singular da linguagem praticada por eles. Algumas palavras, termos ou interjeições identificam o pertencimento de um individuo a um grupo, a um tempo, a um modo e estilo de vida, além de sua conexão com determinados tipos de escolhas. A partir de nossas pesquisas acompanhando o movimento dos jovens nas escolas e fora dela, observamos que há processos de pertencimento e de segregação que se desenvolvem como efeito dos diferentes usos da linguagem. Instigados por esses elementos, isolamos como objeto de pesquisa ${ }^{1}$ a produção linguageira dos jovens para investigar o que há de novo introduzido pelo jovem em relação à linguagem e que ecoa nos espaços de convivência criados por eles na cidade. Em uma das entrevistas, um escritor define a literatura como sendo o "tratamento da imaginação pelas palavras", uma manipulação da língua de maneira oposta àquela operada pela gramática. Nossa pesquisa visa justamente o modo como se dá esse tratamento particular da linguagem por cada um, a partir da linguagem artística urbana.

Sabemos que a forma como uma invenção é feita sobre a língua do Outro repercute sobre os adultos das gerações precedentes. Constitui um fenômeno observável certo mal-estar entre as gerações - pais e filhos, professores e alunos, adultos e adolescentes -, que está frequentemente relacionado às novas formas de uso da linguagem dos jovens. Na escola, o mal-estar entre gerações toma frequentemente a forma da falta de respeito. $O$ novo da linguagem é tomado muitas vezes como desrespeito ou insulto dos alunos contra seus professores. Nossa participação em pesquisas (Braun, Albuquerque \& Santiago, 2016) realizadas no âmbito dos projetos do Núcleo Interdisciplinar de Pesquisa em Psicanálise e Educação (Nipse), permitiu verificar que o desrespeito é um sintoma nas escolas. A Conversação - metodologia da pesquisa-intervenção do Nipse - evidenciou, inclusive, que se trata de um diagnóstico de ambos os protagonistas do processo educativo: os professores se sentem desrespeitados pelo uso que os jovens fazem da linguagem e os jovens, por sua vez, se queixam de não serem escutados e identificam a falta de respeito dos professores na desvalorização conferida à tudo o que dizem.

Diante do contexto apresentado por nossas pesquisas nas escolas, interessou-nos a dimensão de invenção do jovem no campo de suas produções linguageiras para além dos muros escolares. Ou seja, investigar o uso criativo da linguagem juvenil e pesquisar o que há para além daquilo que é tomado e classificado apenas como insulto pelo adulto. Para tanto, tomamos o jovem como um artista que trabalha a matéria linguagem, considerada em suas mais diversas formas: poesia, música, cinema, manifestação, etc. Visamos assim investigar o novo ou a invenção do jovem a partir de suas linguagens artísticas urbanas. A linguagem que está em jogo não se refere a uma 
dimensão pragmática ou meramente comunicativa da linguagem, mas uma outra abordagem da linguagem:

O que começou com a descoberta de Freud foi uma outra abordagem da linguagem, uma outra abordagem da língua cujo sentido só veio à luz com sua retomada por Lacan. Dizer mais do que se sabe, não saber o que se diz, dizer outra coisa do que o que se diz, falar para nada dizer, não são mais, no campo freudiano, as falhas da língua que justificam a criação das línguas formais. São propriedades inelimináveis e positivas do ato de falar. Psicanálise e lógica - uma se funda sobre o que a outra elimina. A análise encontra seu bem nas lixeiras da lógica. Ou, ainda, a análise desencadeia o que a lógica domestica (Miller, 1996, p. 62).

\section{Psicanálise e Arte}

Sabemos da estreita relação entre a psicanálise e a arte. Freud (1907) sempre reconheceu que os poetas e escritores precedem o psicanalista, ou seja, estariam adiantados em matéria de conhecimento da mente por beberem em fontes até então inacessíveis para a ciência. Podemos dizer que, tanto Freud quando Lacan, permitiram que a arte forçasse o avanço da teoria e da prática psicanalítica.

O estilo de Freud abriu o caminho para o encontro entre o psicanalista e a obra literária. A relação entre psicanálise e literatura é marcada por diversas nuances. Por um lado, as obras literárias serviram, por exemplo, para a ilustração dos conceitos psicanalíticos, por outro, a criação literária foi muitas vezes comparada a uma formação do inconsciente, o que produziu uma "psicologia do autor" criticável (Vilela, 2005). Mas a vertente mais interessante é sem dúvida a transformação dos conceitos psicanalíticos a partir da literatura ou de algum outro aspecto da arte. Ainda que Freud tenha sido alvo de fundadas críticas por "interpretar" o texto literário, podemos afirmar que tanto ele quanto Lacan se deixaram interpelar pela arte e abriram o campo para que ela forçasse o avanço da psicanalise. Atraído pelos jogos de palavras, Freud (1905) produziu uma de suas grandes obras sobre os mecanismos linguageiros do inconsciente, totalmente atravessado pelo trabalho sobre a língua que vinham fazendo os escritores alemães de sua época (Mango \& Pontalis, 2004). Os chistes do poeta e escritor alemão Heinrich Heine representam, sem dúvida, ponto fundador e determinante para a produção de Freud (1905).

Jacques Lacan, por sua vez, se deixou interpelar de modo radical pela obra de James Joyce e a partir dela modificou sua concepção a respeito do conceito de sintoma. Vemos aí o encontro entre o pensador da cultura e o clínico, na medida em que se deixa invadir por aquilo da obra que resiste à interpretação, ou seja, a obra de Joyce não é tomada como adorno, mas como suporte para a renovação de um dos principais conceitos da psicanálise (Mandil, 2003).

$\mathrm{O}$ artista, tal como o jovem parece ser aquele que introduz o novo naquilo que é a tradição, 
ou mesmo antecede o novo, captando no ar do tempo aquilo que apenas começa a pairar. Assim, é nesse encontro entre o jovem e sua criação linguageira que esse projeto se sustenta, tomando o jovem como um artista (independente de ter relação direta com a arte ou não), que é aqui definido como aquele que trabalha na matéria linguagem, tal como Heine e Joyce fizeram, forçando o avanço da teoria e da produção acadêmica. Por isso pretendemos também nos deixar atravessar pela produção dos jovens poetas, músicos, cineastas, rapers e seus coletivos em diferentes regiões da cidade.

\section{Diário de campo das entrevistas. Os entrevistados: jovens e escritores}

Com o objetivo de escutar e apreender a relação de cada sujeito com sua produção linguageira, com o modo como conseguiu trabalhar a matéria linguagem em sua juventude, realizamos entrevistas com jovens de diferentes percursos. De um lado, entrevistamos jovens, jovens-adultos, e adolescentes que apresentavam uma relação particular com determinada linguagem. Poesia (sarau), cinema (sobre jovens), rap, ocupação, congado. A intenção era escutar a relação do corpo de cada um com o significante, o modo próprio de trabalhar a linguagem e o lugar que esse trabalho ocupa na vida do sujeito, como por exemplo, a linguagem na sua relação com a entrada ou saída do túnel da adolescência. Por outro lado, nos interessava escutar o que há de novo, de invenção na relação de cada um com o significante, seja a partir da palavra, falada, escrita, recitada, manifestada, dançada, rezada, atuada. Para tanto, precisávamos delinear um conceito de invenção que, tal como uma lente, nos permitisse ler uma possível nuance de novidade. Decidimos então que, paralelamente às entrevistas com os jovens, entrevistaríamos escritores reconhecidos na cidade com o objetivo de construir um conceito de "invenção" que pudesse nos servir como chave de leitura para a análise das entrevistas com os jovens. A fala dos escritores ganhou, entretanto, um contorno inesperado quando nas entrevistas eles começaram a dizer de sua própria relação com a linguagem ou com o trabalho literário. Em alguns momentos essas entrevistas se tornaram um reencontro com o adolescente ou jovem que o escritor foi. Os escritores trouxeram elementos fundamentais acerca da relação com a linguagem para o adolescente ou jovem que eles foram, de sua relação com a escrita, com a invenção e a função da escrita em sua vida. Assim, as entrevistas com os jovens e com os escritores se entrelaçaram, e nos reenviaram, cada uma a seu modo, ao lugar de uma linguagem particular no percurso de um jovem, no passado ou no presente.

Realizamos até o momento oito entrevistas, sendo cinco com jovens (jovem-adulto ou adolescente) e três com escritores reconhecidos na cidade, indicados por pares e com livros publicados. Entre os jovens, um poeta atuante na cena dos saraus; um cineasta; uma raper; um jovem atuante do congado e uma jovem atuante na cena da ocupação de espaços para manifestação.

\section{Lugares de encontro}


Os entrevistados escolheram o lugar de nosso encontro. As entrevistas constituíram pontos de encontro e marcaram um percurso de investigação nosso pela cidade: café, livraria, lanchonete, cinema, casa, universidade, órgão público. Com relação às entrevistas com jovens, duas foram realizadas no campus da UFMG, a pedido dos jovens, uma foi realizada no café de um cinema da cidade, outra em uma lanchonete próxima a uma escola ocupada e a última na casa da avó de um dos entrevistados. Dois dos escritores foram entrevistados em seus locais de trabalho (Órgão do Estado de Minas Gerais e Universidade) e o terceiro no café de uma livraria. Alguns elegeram seu local de trabalho pela facilidade e pela disponibilidade de tempo, intervalo de lanche ou almoço. Outros escolheram lugares na cidade, talvez não por acaso o jovem cineasta tenha proposto um café num cinema, e um dos escritores uma livraria-café da cidade. Com relação à jovem da ocupação, foi a meu convite que nos sentamos numa lanchonete ao lado da escola ocupada, para tomar um suco, com o objetivo mesmo de desocupá-la alguns momentos e possibilitar, nesse respiro, uma conversa sobre sua experiência. Ao final de nosso encontro ela me agradeceu, disse que era fundamental esse convite para se deslocar um pouco e poder pensar sobre o que faziam na ocupação e que deveríamos propor isso mais vezes aos jovens.

\section{O que queremos saber? Jovens: o encontro, o Outro e o novo}

As perguntas colocadas aos jovens nas entrevistas foram concebidas dentro de três eixos: O encontro; O Outro; O novo.

O encontro: o encontro na relação com a sua produção linguageira. $O$ primeiro eixo, denominado "O encontro", diz respeito justamente ao encontro do entrevistado com o tipo de linguagem que nos fez chegar até ele (poesia, cinema, rap, música, etc.). Perguntamos: como tal expressão de linguagem apareceu em sua vida? Como você entrou nessa? Quando foi o primeiro encontro que você teve com isso? O objetivo dessas primeiras perguntas era de localizar, cernir o encontro do sujeito com o tipo de linguagem com a qual ele trabalha e tem afinidade à primeira vista. Diz-se à primeira vista, porque no decorrer das entrevistas descobriu-se, por exemplo, que a relação primordial do jovem cineasta era, antes de mais nada, com a literatura. Enquanto que a relação do jovem poeta dos saraus era com a invenção de histórias e letras de música, e que a relação da jovem ativista das ocupações era com o saber e com a poesia. Ao se procurar um sujeito para entrevistá-lo porque ele tinha uma relação particular com determinada expressão da linguagem, descobriu-se frequentemente que o que o causou e mesmo o levou ao encontro com um determinado tipo de linguagem foi originalmente a relação com outra linguagem.

O Outro: o Outro e a cidade. Nesse eixo, o objetivo é apreender a relação da produção linguageira do jovem com o Outro: seja ele o adulto mais próximo, o Outro social, ou a cidade tomada como Outro. No Outro se conjugam a dimensão do espaço e do lugar no Outro. Do lugar do sujeito no Outro e na cidade. Escutar como essa relação foi acolhida ou não pelo Outro. Compreender como o jovem se vê habitado por uma linguagem que pode ser enigmática para o adulto e que pode 
muitas vezes ser tomada como insulto. Exploramos aqui a posição dos jovens na relação com o Outro. Para tal, perguntamos: você apresentou esse encontro para os adultos à sua volta? Você se sentiu escutado nesse encontro? Você encontrou algum tipo de resistência ou recusa em relação ao seu trabalho? Diante disso, o que te fez perseverar? Você se sente escutado pelos adultos com os quais convive? Quais lugares você mais frequenta na cidade? O que faz neles? Há lugares que você frequenta e nos quais você verifica a produção de invenções linguageiras?

O novo: invenção. No terceiro eixo, na tentativa de nos aproximarmos da ideia de invenção na relação do sujeito com a linguagem, perguntamos: o que você considera inovador na sua relação com essa forma de expressão no mundo? No intuito de conhecer a função de determinada linguagem para o sujeito, perguntamos: quais os usos disso em sua vida? Qual o lugar da produção linguageira (escrita, música, poesia) na sua vida? O que ela representa para você? O que ela te permite? O novo representaria assim um passo a mais em relação ao primeiro eixo "O encontro". O novo visaria apreender o que desse encontro expõe um ponto de novidade, algo de muito próprio e específico de cada sujeito que vem se colocar na cena íntima e na cena urbana.

\section{O desenrolar das entrevistas: encontros e desencontros na linguagem}

Uma primeira característica marcante das entrevistas foi a duração. A maioria dos encontros realizados foram bastante extensos. A menor delas durou por volta de 15 minutos, pois restrita ao horário de lanche no trabalho de um dos escritores, e a maior uma tarde inteira, por volta de três horas. Interessante observar que ainda que a entrevista tenha o objetivo claro de pesquisa, quando uma escuta se instaura, o sujeito passa a falar, e tal fala não se estanca facilmente. Ele vai falar daquilo que foi ou é traumático para ele, da sua história, do que o angustia, etc.

Observamos que os entrevistados raramente respondiam àquilo que era perguntado, quando era perguntado diretamente. Por muitas vezes, tentamos perguntar diretamente qual era a função daquela linguagem para o entrevistado e notamos que a resposta jamais vinha diante de tal pergunta. A resposta a essa pergunta aparecia normalmente em outro momento da entrevista, quando falávamos de outro assunto, quando conseguíamos seguir o fio que tomava a palavra do entrevistado, nos colocando de fato numa posição curiosa e de não saber diante dele. Na entrevista com a jovem adolescente do rap, no momento em que ela conta de um ponto de virada em sua relação com a mãe, quando ela deixa de ser a menininha da mamãe, ela começa a falar que ela e seus amigos "inventam uma nova linguagem". Ao contar sobre algo muito próprio de sua relação com o bairro, o jovem cineasta começa a falar e analisar a linguagem dos jovens moradores da periferia e sua relação com seus modos de gozo. Os entrevistados falam sobre a linguagem justamente a partir de um ponto de passagem ou de virada em suas vidas, e não quando pergunto especificamente sobre essa dimensão. A entrevista com o jovem do sarau foi bastante longa. Ao final, quando ele pede para recitar uma poesia escrita por ele que poderia resumir toda nossa conversa, ele esquece parte da poesia. Aparece aí algo do inesperado, daquilo que falha na nossa 
relação com a linguagem, momentos de irrupção do inconsciente. Um dos raros momentos em que aparece um furo em sua falação.

Assim, ao analisar as entrevistas, encontramos diversas definições de linguagem ou poesia, de trabalho literário e de adolescência com nuances muito próprias de cada um, perguntas que não foram necessariamente feitas, mas que certamente estavam embutidas no desejo de saber da pesquisadora e que apenas surgem quando conseguimos nos deixar guiar pela fala dos entrevistados. Ao falar, por exemplo, sobre como vivenciaram as metamorfoses da fase adolescente, conseguiam delinear uma noção de adolescência, dando seu colorido a esse conceito.

Invenção em 3 dimensões: na saída do túnel, na relação de cada um com a linguagem e na relação da arte com o real. Como a pergunta relacionada à invenção não era respondida diretamente, conseguimos identificar três pontos em que algo de novo parecia ser vislumbrado na fala dos entrevistados. O primeiro ponto é a saída do túnel da adolescência. Nas diversas entrevistas aparece um momento em que os sujeitos saem do estado de completo desnorteio em que se encontram perdidos, errantes, e isso é feito em cada uma das histórias de modo muito particular, bastante único. Em segundo lugar, a relação do sujeito com sua expressão de linguagem também parece alojar um estatuto de novidade, quer dizer, eles criam uma forma de fazer e trabalhar com a linguagem deles. A jovem do rap, por exemplo, nos explicou como fazia rap, explicitando seus modos preferidos de criação: ponto de invenção na relação da pessoa com a sua arte. Encontro contingente do sujeito com algo que abriu a perspectiva. Por último, ao falarem sobre o aspecto de novidade em termos da arte tomada de maneira geral, apontam para algo que se parece com o conceito de "real". Um cinema contaminado pela vida, pelo imprevisível, para escrever tem que ter uma "peça solta", ou ainda, literatura boa é aquela que é tocada pelo real por um encontro contingente.

\section{Escritores: invenção hoje}

Nosso primeiro movimento para apreender as possíveis nuances de invenção embutidas no uso que pode ser feito da linguagem foi procurar nos textos poéticos e literários, ou seja, perguntar ao texto dos escritores. Buscar na poesia uma definição de poesia, na música uma definição de música, no cinema uma definição de cinema, e assim por diante. Em seguida, a partir desse primeiro movimento, pensamos, porque não perguntar aos próprios escritores, reconhecidos na cidade, uma definição atual de linguagem, de poesia, deixar que eles pudessem nos esclarecer quanto à definição atual de um trabalho feito sobre a linguagem. Assim, inicialmente consideramos as entrevistas com os escritores um trabalho de campo paralelo às entrevistas com os jovens, do qual pretendíamos extrair uma concepção de invenção no contemporâneo da linguagem juvenil.

Aos escritores perguntamos por uma definição atual dessa linguagem que é a poesia, ou seja, qual definição eles poderiam dar da poesia hoje? O que se considera poesia hoje é aquilo que se considerava antes? Mudou alguma coisa? Estávamos interessados em saber o que eles observam na linguagem de hoje: a poesia continua do mesmo jeito ou há uma diferença em sua definição 
relacionada às diferentes gerações? Quando é que essa linguagem que está em ação (Benveniste, 1992) tem a dimensão de invenção? A seguir, abordaremos pontos das três entrevistas realizadas com escritores reconhecidos.

Diante do convite para definir ou discorrer sobre a poesia hoje, houve certo embaraço, poderíamos chamar mesmo de uma recusa em fazê-lo. Os escritores se anteciparam em criticar a noção de progresso que poderia estar embutida nesse tipo de pergunta. De certo modo, eles evidenciaram uma concepção que também é a nossa: não utilizar o que os escritores dizem como categoria para avaliar a linguagem dos jovens, visto que é preciso partir daquilo que os próprios jovens estão fazendo. O propósito inicial de tais entrevistas paralelas centrava-se sobre a possibilidade de ter algum "clique" sobre como a relação com o trabalho sobre a linguagem funcionaria hoje. Por fim, os escritores acabaram por nos indicar a relação deles mesmos com a dimensão da invenção.

Um dos três escritores, que não será identificado, pois sua entrevista será analisada na tese na dupla vertente (escritor e jovem), sentiu que trabalhamos num campo extremamente subjetivo a questão da invenção: "Te dei a minha resposta do que é invenção". Chamaremos tal escritor de Oblíquo, dada a relação com a escrita apresentada e elaborada por ele em nosso encontro. 0 inclassificável, o incômodo, o estranho, enfim, o esquisito como dimensão central de sua invenção ficcional. Ao falarem de invenção, os escritores nos apresentaram finalmente não uma concepção do que seria a invenção na linguagem hoje, mas de sua relação mais íntima com a linguagem.

Durante as entrevistas, a partir das perguntas, os entrevistados se deparam com novas nuances de sua relação com a linguagem que até então haviam passado despercebidas ou que não tinham ainda sido formuladas. Este foi um efeito do encontro de nosso desejo de saber com alguns dos entrevistados. O escritor Oblíquo ressaltou em diversos momentos: "nunca falei isso para ninguém", ou marcou: "essa é uma pergunta difícil de responder", ao mesmo tempo em que se mostrava extremamente instigado pela reflexão. Tal escritor revisitou sua infância, seu lugar no desejo dos pais - "estou te contando minha vida inteira". Tocou nos significantes definidores de sua relação com a escrita, identificou pontos que determinaram seu modo de escrever e explicitou a relação entre excesso e falta na relação com o Outro, que está emaranhada em seu processo criativo. Esclarece como determinado conteúdo ou estilo ganha um lugar como material de sua ficção, sendo que alguns traços se repetem em todos os seus livros, quer dizer, algo que era reconhecido pelo Outro, que encontrou um lugar no Outro vai ganhar lugar no modo como ele vai trabalhar a linguagem. Essa entrevista será analisada na tese como uma entrevista com o adolescente ou o jovem que o escritor foi.

O encontro com o escritor Fabrício Marques ${ }^{2}$ aconteceu em seu local de trabalho durante seus 15 minutos de pausa. Chego a seu nome por intermédio do tio de uma amiga, que também é escritor em Belo Horizonte. Nos sentamos para um café numa manhã de um dia útil na lanchonete situada no subsolo de seu trabalho. Durante nossa curta conversa, ele é cumprimentado por vários 
colegas, sendo que um deles diz "bom dia poeta". Começo indagando por uma definição de poesia, a que ele responde com uma poesia. O escritor aponta a dificuldade de uma definição de poesia, ainda que com um recorte temporal, e convida Paulo Leminski para a conversa, ao citar o poema "Limites ao léu". Nesse texto de nome sugestivo, ocioso e descoberto, Leminski (1992) apresenta, ao léu, uma multiplicidade de definições de poesia realizadas por grandes personalidades. Cada tentativa de definição relança a impossibilidade mesma de definição que escorrega para a linha seguinte e que termina com a (in)definição do próprio Leminski, que coloca a sua relação com a linguagem em jogo ao definir a poesia como "a liberdade da minha linguagem". Em outros trechos do poema, a dimensão do impossível e da sutileza, que insiste no âmago da poesia e da própria linguagem, é explicitado: "a fala do infalável" (Goethe); "palavra-coisa" (Sartre); "design de linguagem" (Décio Pignatari); "lo impossibile hecho possible" (Garcia Lorca). A poesia faz o esforço de definir a própria poesia, esforço tocado pela impossibilidade inerente a tal tarefa de definição.

O escritor entrevistado avança na tentativa, sempre fugaz, de uma definição de poesia e vai tecendo ideias em torno de sua própria relação com a linguagem. A poesia remeteria à impossibilidade de se estar inteiramente em um lugar, ou seja, à ideia de não-todo. Sua própria essência seria justamente escapar das tentativas de definição. Para o escritor, a poesia trabalha com a linguagem e tem como objetivo a própria linguagem. Ela seria o estado máximo em que a linguagem pode almejar chegar. Entendemos essa proposição de estado máximo avançada pelo escritor, como o ponto alto, o auge em que o sentido se relaciona com o sem sentido, em que o não-todo-entendido opera para produzir o sublime. A poesia se dá a definir. Parece alojar um buraco por inventar, que dá ao leitor o efeito de fineza da linguagem conectado com algo de seu. Garantia de um furo no qual pode caber uma invenção: do leitor e do escritor.

O ser humano não lida diretamente com o mundo, então a linguagem é, na visão do escritor, uma das formas mais poderosas de se fazer isso, pois ela media o homem e o mundo. E dentro da linguagem, a poesia representaria o momento em que o ser humano brinca com isso que é a linguagem. Nesse ponto, o escritor toca em um aspecto de subversão da poesia, ali onde o homem brinca com o que teria função de instrumento e vai se permitir jogar com o limite da linguagem, ver do que ela é capaz, experimentar transformá-la enquanto é transformado por ela. Após essas tentativas de cernir os conceitos de linguagem e de poesia, o escritor conclui que a poesia se apropria das inovações tecnológicas, mas isso não faz dela necessariamente uma poesia "moderna". O fato de usar recursos novos não faz com que uma poesia seja "nova". Desde essa primeira entrevista realizada com o escritor Fabrício Marques, o desafio para cernir a invenção na poesia hoje é colocado. A dimensão do novo aparece um tanto opaca. O que parece haver "de novo" é o caráter de invenção inerente a poesia atemporalmente, ou seja, é isso que ela guarda de indefinição, de impossível a definir, que a torna desde sempre o ponto alto da linguagem. Para quem escreve e para quem lê. Em silêncio, ou em voz alta. 
Fabrício avança um ponto de diferença em relação ao passado: hoje o leitor tem um papel não só mais ativo, mas determinante no reconhecimento do escritor e na constituição do estatuto de "obra" para uma produção artística. Essa seria uma dimensão contemporânea potencializada pelo efeito da internet: a ideia da produção do artista pelo público, ou seja, quem faz o artista é o público e não tanto a consistência prévia de uma obra. No contexto digital, o público é não apenas receptor, mas produtor e emissor de conteúdo (Fogel \& Patino, 2013). Assim, uma vez que o público gosta e compartilha, determinado jovem torna-se uma celebridade, um artista, independentemente de ter ou não uma obra primeiramente reconhecida.

Conversamos ainda sobre os impasses na educação diante do conflito linguageiro entre as gerações e da existência de minorias na linguagem que são desprezadas por parte da sociedade. Ele fala de sua relação com a filha adolescente e do giro necessário para não tomar como insulto imediatamente aquilo que pode ser um modo de fala, um dos usos que os jovens estão fazendo da língua. Ao final de nosso encontro, Fabrício me conta de seu livro Uma cidade se inventa (Marques, 2015), que teria uma relação com meu objeto de pesquisa: a linguagem e a cidade. Saio de seu trabalho e dou um pulo na livraria ao lado para comprar o único exemplar disponível. Seu livro trata justamente da cartografia literária de Belo Horizonte, e da invenção de uma cidade saída da relação dos escritores com os espaços urbanos. Retomaremos um pouco algumas ideias de seu livro ao falarmos da relação dos jovens com o viaduto Santa Tereza.

Encontro com Ana Elisa Ribeiro ${ }^{3}$ na universidade em que ela leciona. Iniciamos nossa conversa em uma lanchonete barulhenta, repleta de alunos que aguardavam o início das aulas noturnas. Uma colega dela se aproxima e elas conversam um pouco sobre o desafio de ser professor. Conversamos por um tempo ali e depois procuramos um lugar mais tranquilo. Acabamos nos sentando nos degraus de uma escada. Nossa conversa durou mais de uma hora e levou certo tempo para que eu conseguisse chegar à pergunta sobre a invenção hoje. A entrevistada discorreu bastante tempo sobre a ideia do "eterno iniciante" no campo da escrita e como a denominação que insiste, vinda do Outro, de "jovem escritora", a incomoda. Ela esclarece que aquele que é tomado como "jovem" no campo literário é quem não teve visibilidade (ainda) na grande mídia, independentemente do percurso, dos anos de escrita e dos livros publicados. Esse ponto do (não) reconhecimento do Outro pareceu tocá-la profundamente.

A escritora entrevistada concorda que é muito difícil dizer algo sobre o que seria uma poesia atual. Ela entende que não é possível enxergar com clareza o que está acontecendo hoje e que um mapeamento viria num tempo depois. Ou seja, apenas será possível mapear uma dimensão de invenção mais tarde, no après-coup, quando não pertencermos mais a esse tempo. Ana Elisa identifica na escrita dos mais jovens uma forte presença das questões sociais e de questões ligadas ao feminino, ao ser mulher, mas que o cenário para quem está imerso nele é sempre uma "névoa". Insisto, perguntando por algo que foi introduzido de novo ou que a tenha estranhado ou capturado, algo de diferente que ela tenha lido recentemente. A escritora reconhece algumas pessoas, de quem 
considera o texto interessante. Cita Ana Martins Marques, Norma de Souza Lopes e outras escritoras de uma geração mais recente, tal como Bruna Kalil ou Regina Azevedo. Embora considere essas referências, não enxerga algo completamente inventivo ou novas experiências de linguagem. Entretanto, destaca os efeitos do mundo virtual como índice de uma dimensão de novidade, sobretudo no que tange à potência de articulação na internet: escritores muito jovens, adolescentes que se tornam reconhecidos e admirados por grandes escritores consagrados, que arrastam multidões para saraus de poesia ou lançamentos de livros e que possuem milhares de seguidores nas redes sociais.

Quando conversamos sobre o que seria um trabalho literário, um trabalho sobre a linguagem, ela traz a ideia de que é preciso ter uma "peça solta". Nesse ponto penso que ela fala de sua relação com a escrita, uma intimidade com a linguagem que permite experimentar, trocar, surpreender, tirar as coisas de seu lugar, usar a palavra de um jeito antes inimaginável. Uma intimidade com a linguagem que não se aprende na escola. Ao aprofundarmos sobre a noção da peça solta, ela traz a ideia de não obediência, trabalhar sobre a linguagem implica a dimensão da desobediência. Peça solta é uma expressão que parece remeter a alguma traço ou relação com a loucura, ponto a ser investigado. É possível contar uma história, descrever, sem necessariamente trabalhar a linguagem. Isso a fez pensar em Clarice Lispector, que contava histórias banais de um jeito intenso, surpreendente e imprevisível e, sem dúvida, muito próprio. Nesse ponto da conversa, vai aparecendo algo do novo, da invenção, pela qual venho perguntando desde o início da entrevista. Justamente quando paro de perguntar por uma definição de invenção é quando ela se permite falar de sua própria relação com a linguagem, ou com um tipo de trabalho com a linguagem que a interessa.

Para Ana Elisa, o trabalho sobre a linguagem remete ao modo como a pessoa consegue fazer o jogo entre as palavras funcionar, como articula aquilo que quer dizer com o como fazê-lo, ao modo como conecta elementos com liberdade, ao fato de transparecer o domínio dos recursos linguísticos utilizados. Escuto que o trabalho sobre a linguagem abarcaria a ideia da introdução de algo muito pessoal, singular, algo de seu. Pergunto se isso seria o estilo. Ela traz a ideia de que há sempre uma tentativa de referenciar um escritor ao outro, ou a um outro já reconhecido, e que em alguns momentos aparece uma voz para a qual você não encontra rapidamente um encaixe. Procurase uma referência similar para tal voz e não encontra. Escutei aí algo da invenção, de fato atemporal, no tempo de cada escritor, na relação com sua escrita.

Ao final da entrevista, o ponto da desobediência retorna do uso inesperado da linguagem. Entendo que aí falamos sem falar diretamente da invenção, o motivo de nosso encontro. Ana Elisa marca a dificuldade de traçar uma fotografia desse "negócio", e isso abre caminho para que surja um pouco sobre sua relação com a linguagem. Ela conta que sempre leu muito em voz alta e que faz isso até hoje para ficar ouvindo a língua. Para dar lugar a uma percepção sonora, de ritmo e de voz que não se tem normalmente ao ler em silêncio. De outro modo não é possível perceber a força 
que "aquilo tem", o impacto da frase, as diferentes formas como uma mesma frase pode soar. Ela marca como é difícil encontrar um outro que possa te ajudar a fazer com isso, é algo que cabe a cada um fazer, aprender, e claro, depois acontece um encontro com um grupo, com pessoas para formar uma turma. O contato com "isso" que a leitura em voz alta proporcionou à Ana Elisa me pareceu traçar a fotografia, ainda que embaçada, do encontro com um jeito muito próprio de amortecer e amplificar o impacto da palavra.

\section{Viaduto atualizado pelos jovens}

Pensamos que para cada habitante há uma cidade particular, um mapa sentimental recortado por sua história de vida, uma cidade construída por seus passos no urbano e inventada por sua imaginação (Kehl, 2015). Entendemos que essa cidade íntima se conecta com uma cidade compartilhada justamente por algum tipo de linguagem particular (música, literatura, poesia, etc.). É a arte, o artista, e a fineza da palavra que fazem a conexão entre a cidade de cada um e a cidade compartilhada por todos os cidadãos.

Para cada jovem uma cidade se inventa, e essa possível invenção resulta sempre de um entrelaçamento da tradição com o novo. Cada geração que anda por um espaço urbano introduz aí sua forma de viver a cidade, sua maneira de estar com o outro, de estar no campo do Outro. Andar pela cidade é, finalmente, uma forma de escrita, inscrever seu corpo, habitar lugares e modificar o próprio espaço, vasculhar o corpo da cidade. Antes dos jovens que entrevistamos nesta pesquisa, várias gerações de escritores e poetas inscreveram lugares na cartografia literária de Belo Horizonte. Seus atos e seus lugares preferidos escreveram uma outra cidade, uma cidade como linguagem própria (Marques, 2015). Assim, há uma linguagem própria da cidade, uma linguagem que resulta de seu passado e da história calada de suas populações (Kehl, 2015). Ao escalar o viaduto Santa Tereza, Carlos Drummond de Andrade constrói de modo literário Belo Horizonte, e marca de maneira perene a relação entre a experiência urbana e a literatura moderna (Marques, 2015). Muitos foram os poemas, contos e crônicas surgidos da relação dos jovens escritores com o espaço urbano, produções que ajudaram a construir o imaginário de uma cidade para seus moradores.

Na Belo Horizonte de ontem, jovens escritores deram uma resposta da literatura à cidade que encontraram no tempo de sua juventude. Escalaram arcos em sinal de protesto, produziram escritos que denunciaram como uma cidade recém-nascida podia se mostrar tão ultrapassada no uso e compartilhamento de seus espaços. Drummond, Pedro Nava e Cyro dos Anjos, em seu desatino juvenil, fizeram parte do movimento de ocupação do espaço cultural da Belo Horizonte dos anos 20: a rua da Bahia nunca mais foi a mesma (Marques, 2015).

O viaduto Santa Tereza sofreu uma potente atualização (Levy, 1995) pelos jovens de hoje. Ele se tornou ponto de encontro, de ação e de manifestação dos jovens que se preocupam com o uso do espaço público na cidade em que vivem (Perdigão, 2016). Ao buscarem novas formas de vivenciar a cidade, os jovens atualizaram (Castro, 2016) o uso do viaduto. Se antes Drummond e os 
escritores subiam os arcos, agora os jovens ocupam os subterrâneos do viaduto, transformando e desviando o uso desse espaço. Os jovens desceram os arcos escalados pelos escritores, numa descida radical até o subsolo, fizeram viver e pulsar a cidade a partir "debaixo". O movimento feito pelos jovens atualiza um espaço que deixa de ser apenas uma via de passagem para tornar-se palco de discussão acerca do uso dos espaços públicos em Belo Horizonte (Perdigão, 2016).

\section{A lógica de saída do túnel da adolescência}

Temos acompanhado as produções linguageiras dos jovens. Interessa-nos ler o novo dessa produção a partir dos encontros contingentes e daquilo que deles reverbera na cidade. Extraímos das entrevistas uma lógica em 4 tempos de percurso do túnel da adolescência. Tempo 1: errância. Tempo 2: ponto de ancoragem. Tempo 3: saída do túnel da adolescência. Tempo 4: o sujeito se apresenta com o que é dele - invenção.

A seguir, um fragmento da entrevista com uma jovem do duelo de MCs, duelo que se consolidou a partir da ocupação subterrânea do viaduto Santa Tereza pelos jovens. Tempo 1. Ao falar sobre seu encontro com o rap, a adolescente contou que "foi num período meio conturbado", momento em que ela e o irmão se viram muito afetados pela separação dos pais. Ela se vê "perdida na imensidão" da adolescência. Descobre a traição do pai, conta para mãe e o vê sair de casa, abandonando-os, sem conseguir separar as coisas. Quando pequena, queria ser igual ao pai, que tocava na igreja. Idealizava os pais cantando juntos no altar. Admirava os tios músicos, mas que não conseguiam viver da música, seu "sonho de criança". Sempre gostou de rap, mas nunca tinha feito "prática da parada". Sua vida está sem "norte".

Tempo 2. Foi um tio que "me aplicou um dos primeiros sons, tirando o Racionais que é o que a gente escuta sempre né, na quebrada". O som que o tio aplicou foi o da Flora Matos: "ele falou, escuta essa mina, é um som que chama 'Mundo pequeno', que é assim bem, bem foda, que foi o que me fisgou assim, eu, opa, essa mina é foda". A fala captada a partir da indicação foi "essa mina é foda". Ela canta parte da música: "o mundo é tão pequeno, pras vontades que eu venho tendo, nem eu entendo, todo dia eu me surpreendo, parece que eu nem tô mas o fato é que eu tô te vendo...". Digo que a música parece ter a ver com o momento da adolescência, ela diz: "É porque a gente sonha demais, a gente quer demais e parece que o mundo fica pequeno diante disso, sacou? Porque o mundo é só o mundo, o meu sonho é o meu mundo". O tio apresenta uma música "foda" que é recebida como uma indicação de uma mulher "foda", que traduz em sua letra algo que a toca. $O$ encontro contingente com a ideia que o tio tem da mulher que ela quer ser produz efeitos em seu destino. $O$ desejo do tio, um curador para sua arte, vai de encontro com algo que é dela: descoberta de algo no Outro. A partir das buscas na internet, orientadas por aquilo que ressoou da fala do tio em seu corpo, o "youtube vai relacionando as coisas" e ela chega aos duelos de MCs: "como é que esse cara faz isso véio, na hora, ao vivo". 
Tempo 3. De expectadora do Duelo no youtube, ela vai ao viaduto escondida da mãe e lá encontra um jovem. "Mano, o que vai rolar aqui?". Ele responde: "é a marcha da maconha". De repente, ela diz que sabe rimar, ele responde "então rima aí, deixa eu ver". Ela, que nunca tinha rimado em público, rima e o interlocutor se surpreende "nó, você rima demais, você tem que escrever". Escreve então sua primeira música e começa a batalhar. O viaduto (aquele do Drummond) se tornou um ponto de encontro para além do duelo, um ponto a partir do qual ela aprendeu a se virar com a "maldade" do centro. Tem um jeito de se virar com a rua, saber até onde ir, mas "tem que estar pronto para correr".

Tempo 4. Ao começar a frequentar os eventos de rap ela encontra uma "galera diferente", e decide: "eu vou ser quem eu quero ser". "Reviravolta"! Deixa de fazer tudo para agradar a mãe, muda o jeito de se vestir e de falar, e diz do encontro com os pares que "A gente cria uma nova linguagem" para além do rap. Passa a rimar a seu modo: gosta de criar a partir do que o outro diz, "linkado", com tática, sem ofensa, foge do óbvio. Faz parceria com o irmão. A adolescente se torna uma MC reconhecida pela geração anterior do rap e pela mídia, circula pelo Brasil, ganha visibilidade que os tios não tiveram. De perdida na imensidão adolescente para o mundão, sua saída foi "Tudo o que eu não conseguia falar, eu escrevia, e é assim até hoje", uma mina foda que rima e anda no centro.

\section{Conclusão}

A proposta do presente artigo foi delinear o panorama de nosso percurso de entrevistas no campo das linguagens artísticas urbanas, por isso, o título - um diário de campo. Explicitar elementos que se destacaram no campo de nossa pesquisa de doutorado, ainda em andamento, para que, ao se transformarem em material de reflexão e elaboração, pudessem apontar o caminho para a saída do fim do túnel da tese. Relatamos nosso encontro com escritores e jovens pela cidade com o intuito de apreender o modo como se dá o tratamento particular da linguagem feito por cada sujeito. Para tanto, elegemos a dimensão da invenção a partir das linguagens artísticas urbanas. Não se trata ainda de uma análise minuciosa dos dados das entrevistas, tal processo será realizado na construção da tese.

Propusemos uma introdução às entrevistas, ou seja, contar a história das mesmas, um tempo que precede a sua análise propriamente dita, mas não menos importante, pois permite apreender as perguntas realizadas, as perguntas não respondidas, o modo como as respostas para algumas perguntas cruciais não apareciam no momento em que realizávamos tais perguntas. Ou seja, os sujeitos não respondem aquilo que queremos saber quando perguntamos diretamente. Apresentamos dois momentos. Primeiro, a leitura daquilo que observamos e aprendemos com o percurso das entrevistas: quem entrevistamos, o que queríamos saber, efeitos dos encontros e desencontros. Em um segundo momento, aquilo que foi possível isolar: encontramos nas entrevistas uma lógica de saída do túnel adolescente que articula adolescência, linguagem e invenção, os três 
grandes temas constituintes da tese. Tal lógica foi apresentada por meio de um fragmento de uma entrevista com uma jovem do rap. Temos em quatro tempos: errância; ponto de ancoragem; saída do túnel; e por fim, o jovem se apresenta com o que é dele - invenção. A dimensão da invenção nas entrevistas parece se colocar como um passo a mais em relação à saída do túnel, como constituída a partir do mais íntimo de cada sujeito - ponto de investigação.

\section{Notas:}

${ }^{1}$ Pesquisa de doutorado em andamento em Conhecimento e Inclusão Social em Educação pela Faculdade de Educação (FaE) da Universidade Federal de Minas Gerais (UFMG). Orientação: Ana Lydia Santiago.

${ }^{2}$ Escritor e jornalista, com doutorado em Literatura Comparada pela Universidade Federal de Minas Gerais, reside em Belo Horizonte.

${ }^{3}$ Escritora e professora doutora universitária, reside em Belo Horizonte.

\section{Referências Bibliográficas}

Benveniste, E. (1992). O homem na linguagem. Lisboa: Vega Universidade.

Braun, L.; Albuquerque, B. S. \& Santiago, A. L. (2016). Adolescência e o corpo falante: o que se faz com menino atentado? Curinga, 41, 139-149. Belo Horizonte: EBP.

Castro, L. (2016). O uso desviado do espaço. (Dissertação de mestrado não publicada). Escola de Arquitetura, Universidade Federal de Minas Gerais, Belo Horizonte.

Fogel, J.-F. \& Patino, B. (2013). La condition numérique. Paris: Grasset.

Freud, S. (1996). Os chistes e sua relação com o inconsciente. In J. Salomão (Trad). Edição Standard Brasileira das Obras Psicológicas Completas de Sigmund Freud (Vol. VIII). Rio de Janeiro: Imago (Trabalho original publicado em 1905).

Freud, S. (1907). Delírios e sonhos na "Gradiva" de Jensen. In J. Salomão (Trad.) Edição Standard Brasileira das Obras Psicológicas Completas de Sigmund Freud (Vol. IX, pp. 15-88). Rio de Janeiro: Imago (Trabalho original publicado em 1907).

Kehl, M. R. (2015). Olhar no olho do outro. PISEAGRAMA, 07, 22-31.

Leminski, P. (1991). La vie en close. São Paulo: Brasiliense.

Lévy, P. (1995). O que é o virtual? São Paulo: Editora 34.

Mandil, R. (2003). Os efeitos da letra: Lacan leitor de Joyce. Rio de Janeiro/Belo Horizonte: Contracapa Livraria/Faculdade de Letras UFMG.

Mango, E. G. \& Pontalis, J.-B. (2014). Freud com os escritores. São Paulo: Três estrelas.

Marques, F. (2015). Uma cidade se inventa: Belo Horizonte na visão de seus escritores. Belo Horizonte: Editora Scriptum.

Matos, F. O mundo é tão pequeno. Recuperado de: https://www.ouvirmusica.com.br/flora-matos/omundo-e-tao-pequeno/. 
Miller, J.-A. (1996). Matemas I. Rio de Janeiro: Zahar.

Perdigão, J. (2016). Viaduto Santa Tereza. Belo Horizonte: Conceito.

Vilela, Y. (2005). Pascal Quignard e lalangue. Almanaque de Psicanálise e Saúde Mental, 10, 73-80.

Belo Horizonte: EBP/IPSM.

Citacão/Citation: Albuquerque, B. S \& Santiago, A. L. (mai. a out. 2017). Jovens, escritores e a invenção nas linguagens artísticas urbanas - um diário de campo. Revista aSEPHallus de Orientação Lacaniana, 12(24), 5166. Disponível em www.isepol.com/asephallus. doi: 10.17852/1809-709x.2019v12n24p51-66.

Editor do artigo: Tania Coelho dos Santos.

Recebido/Received: 26/08/2017 / 08/26/2017.

Aceito/Accepted: 10/09/2017 / 09/10/2017.

Copyright: ( 2013 Associação Núcleo Sephora de Pesquisa sobre o moderno e o contemporâneo. Este é um artigo de livre acesso, que permite uso irrestrito, distribuição e reprodução em qualquer meio, desde que 0 autor e a fonte sejam citados/This is an open-access article, which permites unrestricted use, distribution, and reproduction in any medium, provided the author and source are credited. 